or neglect, of the opportunities provided by scientific discovery. Neither physicist, economist, nor sociologist is competent alone for this task. A combination of the three might do much to direct the stream of progress into the happiest channels.

\section{SOCIAL SCIENCE, STATISTICS AND POPULATION PROBLEMS}

\section{BY D. CARADOG JONES}

\section{School of Social Sciences and Administration, University of Liverpool}

$\mathrm{T}$ HE vice-chancellor of one of our modern univer sities has been heard to state on more than one occasion that he has failed to discover what is meant by social science. In a lesser man that might be taken as lack of appreciation of a field of knowledge fraught with immense consequences to mankind; but in this case it was no doubt intended as a criticism of social scientists because they have not defined with any precision the boundaries between their own and other sciences. That is not surprising in view of the rapid development of interest in the study of sociology. Interpreted widely, as it should be, it would include any branch of knowledge concerning man regarded as a social animal, in short, the study of human groups. Although, for convenience of observation, individuals may be isolated, interest centres in their social behaviour, their relationship to other individuals similar in many respects to themselves. But the diversity between them, in temperament, in outlook, in aims, is of even greater importance than the likeness. It is these differences, if not delicately handled, that produce strains and ruptures-strikes, wars and revolutions-in the body politic. There is an attraction in superficial remedies for such conditions, but they do not last. We spend our energy too often upon the perfecting of the machinery of social life, while neglecting the source and spring of all motivization : it is like designing a car, stream-lined and beautiful in all its parts, only to find that we have no suitable fuel to make it run smoothly. One of the most fundamental of the social sciences is psychology, because it explores the nature and causes of the divergences between individuals in their innermost citadel where they are most intimately revealed.

Another fundamental social science is philosophy, which creates harmony out of an assembly of seemingly discordant voices. This is achieved by discovering the purpose of life and so relating a diversity of means to a single-minded end. The individual converted, the right leader found, it can turn a mob into a disciplined army; but the purpose of the army is not to wage war upon some other faction. This social philosophy is essentially moral : it takes all the world as its parish, for in the realm of science there can be no partisanship. The warfare will not be against flesh and blood, but against ignorance and disease of mind and body, a ceaseless campaign systematically waged to get the best out of the rich natural resources available for the well-being of all mankind.

Assuming the philosopher to have contributed his share to the shaping of the new world, the political scientist will next be called upon to design regional and international instruments capable of transmuting the philosopher's ideal plan into realized fact; the public administrator will assume responsibility for the right use and control of these instruments ; and jurists will codify agreed rules to regulate social behaviour. As the curtain unfolds, the stage is seen to be set for actors almost without number, and each must play his part. The social historian warns us against the purchase of experience at too dear a price; he would have us profit by the mistakes committed in the past. The geographer deals with the reactions of human groups to their environment; it is his task to make an inventory of the raw materials latent in land and sea, to consider the most profitable use to be made of them, and to determine whether some areas are not too densely packed in view of their resources while others are starved of people to develop them adequately. Problems concerning the distribution and exchange of commodities come within the province of the economist; while the town planner contrives to apportion the land wisely to different uses, thereby preventing that haphazard building which has so frequently distorted the natural beauty of the countryside.

Hitherto we have failed to make a success of world government, not because we have lacked experts in all the social sciences mentioned, but because it has been nobody's business to survey the world as a whole and to co-ordinate the activities of these experts so that they work to a common plan. There has been another reason for failure: we have interpreted wealth in material terms and not in terms of human satisfaction. Economists and statisticians must take their share of the blame because, in comparing the standard of living of one class with another or the national income of one country with another, they have used money value as their measuring rodwith this much justification, that it seemed to be the only means of accurate measurement to hand. Yet, taken alone, it can be but a very imperfect index of what is really valuable in life. If we are to take true stock of a country's wealth, should we not start with the people who inhabit it? Apart from them, no other kind of wealth has sense or meaning.

So far this review has been in general terms. When we come down to practical details, we quickly discover large gaps in our machinery for making a satisfactory survey of the resources of even a small part of our own Empire, leaving other countries out of the account. Yet, to undertake such a continuous survey should be one of the main functions of the social scientist. Acting on the principle already enunciated, the most important feature of this stocktaking would be to trace the trend of population, in size and character. It was well known before the present War began that the population of Great Britain, in common with that of most other European countries, was fast approaching a decline, and the War its.If will have gravely aggravated this condition. But population must always be considered in relation to the area occupied and to the stage of culture reached. With that in mind, the ques ion arisesHow shall optimum population be defined ? And, having defined it, how shall it be achieved and how maintained ? Clearly the optimum is not merely a matter of size. More important than their number is the quality of the people who inhabit any country. But quality varies from class to class, from individual to individual, and even from age to age in the same individual. Hence, as a first step towards a definition of the optimum, it would be well to try to assess the size and quality of the actual population at some 


\section{No. 3769 , JANUARY 24, 1942}

given date, and to measure the effect upon it of a changing environment, Until such periodical assessments can be made over a sufficient interval of time, we shall be working to a large extent in the dark, lacking any standards or axis of reference.

How far do we take stock of the human wealth of the nation at present? The census provides us with a reasonably accurate count of the people every ten years, and enables us to classify them by location and by households. The population can also be split up into age groups, by sex, marriage condition and occupation. This gives us a photographic record at the date when the count is taken. In addition, day by day during intercensal periods, there is a legal obligation to register every new birth, marriage and death, and very few, in fact, escape registration. But, wasteful as it seems, these records have hitherto been kept in isolation from each other and from the census returns. There are, no doubt, administrative and other difficulties in linking them together, but these should not prove insuperable tasks.

Since $\theta$ very marriage starts a new family, the potential source of new wealth, and birth represents the actual creation, while death is the destruction, of human wealth, the State should keep as complete an account of these vitally important events as any efficient business firm does of its gain or loss of material goods, and should relate them to one another. This could be accomplished if, at every registration of a marriage or death, the law required the production of copies of the birth certificates of the persons concerned, and at every registration of a birth the production of a copy of the civil registration of marriage. It would be possible then to start a card index of each family at its foundation on marriage, and to keep it up to date by adding fresh records of birth, marriage or death as they occurred, until each member of the family; parents and children, passed out by death or started a new card by marriage.

The family, though the smallest, is undeniably the most important unit of social life, and these family cards, when analysed by random samples-drawn from different districts, or from different occupational groups determined by the occupation of the head of the household-would provide a rich mine of research material for students of social science. Important differences in marriage tendency, in fertility, in the incidence of mortality would come to light, and we should be in a much better position than we are now to say which sections of the community are contributing most and which least to the population of the future. Associated with individual identity-cards, such a scientific registration scheme could be used also to keep track of movement from one region to another, and of migration into and out of the country, as does the admirable system of registration which has been in use for some years in Sweden. No names, of course, would be disclosed; the material would be used solely for administrative and research purposes.

Periodical surveys should also be made of random samples of different classes of the population, in order to determine what is representative of each class-and the amount of variation from the average -in physique, nutrition, health, intelligence, temperament, character. In war-time the need for a detailed examination of the physique and health of all applicants to join the services is recognized as imperative. The need is no less in times of peace, but any such medical inspection is then confined in general to children of school age and those who take up certain types of occupation. In the task of establishing authoritative standards or norms of physique, nutrition, and health, by the analysis of selected random samples, the statistician will have to lend his aid to specialists in health and nutrition.

When we go on to consider the measurement of intelligence, our difficulties increase. The more important the quality to be measured, the less satisfactory are our instruments for the purpose. Some headway has been made in devising intelligence tests for the young, and we can certainly start by making as complete a survey as possible of the rising generation. But considerable research is still needed before we discover satisfactory devices for the assessment of temperament and character. Yet it is only when we reach the stage of trying to measure any such characteristic, however imperfectly, that we find ourselves impelled to seek to understand its true meaning and to define it in terms free from ambiguity.

Stress has been laid in this article on the importance of taking periodical stock of the population, because it is mainly in the people that the interest of the social scientist lies. But the people express themselves in their institutions and in what they make and do, so that our national stock-taking would be incomplete without a survey of all other forms of wealth. This opens up still wider vistas for investigation. The young hold the key to the future; we must therefore examine whether our educational system is such that we make the best use of the human material at our disposal. Pushing the inquiry further back-Is the training given to our teachers the most suitable for its purpose, and are they chosen in the best possible way? There is urgent noed also to ask why, as man's capacity to produce grows, industrial depressions are intensified. What are the frustrations which prevent the free flow and exchange of goods and services? Are the ruling factors economic, dependent upon the improper adaptation of money to its purpose and the unwise handling of facilities for the creation of credit, or are they associated with selfishness, the power of monopoly and vested interests, possibly misguided even from the point of view of their own self-interest ? Again, as opportunity for rest and recreation increases, are we learning to use it to better advantage ? Under a machine economy the pace of work and of living generally is vastly accelerated. How is rest for the mind and for the nervous system to be obtained ? Are these questions that can be settled by the medical man only or have they a psychological or spiritual basis?

So wide and intricate are the problems involved in any survey on the scale contemplated that the co-operation of experts in many fields would be essential to unravel them. A central research institute, if of independent status like a university, and adequately financed, would undoubtedly attract the sorvices of distinguished men of science. It should have a permanent staff; but it should be able to enlist also the aid of other social scientists, whether in universities or associated with such bodies as have already been founded by private benefaction for the purpose of social research. In order to prevent overlapping and to secure comparability of results in all such inquiries, it would be the function of the central institute to encourage co-ordination and concerted 
planning. Along these lines it should be possible in due course not only to ascertain the value of our possessions but also to get some idea of the potential capacity of our people, and thereby to raise the general standard of living and national culture to a much higher level than we have yet achieved.

\section{ETHICAL AND POLITICAL REMODELLING OF SOCIETY}

\section{By SIR FREDERIC KENYON, G.B.E., K.C.B., F.B.A.}

7 HE rehabilitation of a wrecked and bewildered world will be the task of the years which lie immediately before us. In 1919 we hoped that we might restore the world as it was before 1914, with additional provision for its security. In 1942 we know that that attempt failed, and that when the present threat to civilization has been defeated it will be necessary not to restore an old world but to lay the foundations of a new one. A movement which has been in progress for a generation has been greatly accelerated. The foundations of society have been broken up. A new outlook on social relations has become necessary, and we have to orient ourselves in the new circumstances.

Up to the outbreak of the War of 1914-18 we were in effect living on the Liberal philosophy and political economy of the middle of the nineteenth century. Its corner-stones were individualism, laisser-faire and free trade; its prophets were Mill, Herbert Spэncer, Fawcett. The State should interfere as little as possible. The individual should be left to develop in his own way; to buy in the cheapest market and sell in the dearest; to aim at material welfare and let the devil take the hindmost. It was a philosophy unimpeachable if once you accepted its fundamental axiom, that the whole duty of man is to cultivate material prospэrity. Its best exponents recognized that the 'economic man', for whose conduct they enunciated principles, was not necessarily the whole man; but the politicians and the popularizers of scientific thought ignored this qualification, and for some three generations these doctrines governed the thought and the political practice of the nation.

There were always some-Carlyle, Ruskin and the Christian Socialists notably — who combated a political economy which they accused of being soulless. There were always some who maintained that, while unrestrained individualism was good for the strong and might bring wealth to a State, it involved unjustifiable suffering for the weak. A sense of social responsibility began to grow, and took visible form in the 'eighties, in such movements as the Salvation Army and the foundation of university settlements. Gradually, almost unconsciously, the State and the local administrations accepted more and more responsibility for the welfare of the people. The 'social services' assumed an ever-increasing importance in national and local budgets, which meant in fact that the larger incomss ware curtailed for the benefit of the smaller. The War of 1914-18 intensified this movement; it gathered strength in the uneasy years of peace from 1918 until 1939; and with the now War it has come with a rush. The State has assumed control of nearly every form of activity. Large incomss are taxed to the verge of extinction. Hundreds of millions are drawn from the profits of individuals and companies and applied to keeping down prices for the poorer classes and increasing their earnings. The exigencies of war have brought us to accept, almost overnight and without a atruggle, an almost complete measure of national socialism, and a very extensive levelling up and down of incomes. The problem now before us is, how much of this remodelling of society should and could be carried forward into the years of peace which will follow when once the forces of evil, with which we are engaged in a death-struggle, have been overcome.

The great danger is lest this problem should be approached under the old forms of political controversy, with the leaders of each party striving to stake out claims for those whom they represent, and to turn to their material advantage the opportunities of the moment. This, by whatever party it is practised - employer or employed, capital or labour, the 'haves' or the 'have-nots'-is war profiteering, the turning of the exigencies of war to one's own material profit. It may be more justifiable on one side than on the other; but the basis is the same, the nineteenthcentury doctrine that everyone should do the best he can for his own material advantage.

The remedy needed is something far more fundamental. We have been so saturated with the doctrine that material welfare is the prime aim of life that we do not realize that it has not always been so. Material welfare has, no doubt, always been a motive of human action, and often a powerful one, but it has by no means always been the predominant one. It has not always been held that man lives for bread alone, or that "they should take who have the power, and they should keep who can". We know now to what the unrestricted application of this doctrine has led us. We want now to reconsider its validity, objectively and impartially, and to determine how it can be improved or replaced.

We want, in fact, a new political philosophy ; and in this phrase the epithet is not used in the restricted sense of parliamentary and municipal controversies, "where ignorant armies clash by night", but in the sense in which "politics" means the art of living together in a civilized and organized community. This art has to be thought out afresh, and the thought needs to be as unimpassioned as possible. It is also of the first importance that the thinking and the formulating of its results should be done without delay, in order that the field may not be pre-occupied by the combatant politicians (in the narrower sense), and that the results of dispassionate thought may be at the service of the statesmen who eventually have to lead the reconstruction of our national life.

It is for this reason that the establishment of some form of central organization of sociology seems to many persons to be a desideratum. Just as the Institute of International Affairs serves a useful purpose in the collection of facts and the formation of opinion on international matters, and as institutes of archæology or chemistry or chartered accountancy bring together those who are interested in these subjects for the interchange of views, so a similar organization for sociology would serve as a forum for the formation of the new philosophy of social relations which seems to be needed. This is not so unpractical a proposal as it may seem to those who are satisfied with the limited vision of immediate controversy. It does not mean that long-bearded and unpractical scholars will sit down to elaborate papər constitutions or new Utopias. It means rather that those who are engaged in social activities will pool their experiences, will be invited to formulate 